Jul 1st, 12:00 AM

\title{
Integration of MONERIS and GREAT-ER in the Decision Support System for the German Elbe River Basin
}

Jürgen Berlekamp

Neil Graf

Oliver Hess

Sven Lautenbach

Silke Reimer

See next page for additional authors

Follow this and additional works at: https://scholarsarchive.byu.edu/iemssconference

Berlekamp, Jürgen; Graf, Neil; Hess, Oliver; Lautenbach, Sven; Reimer, Silke; and Matthies, Michael, "Integration of MONERIS and GREAT-ER in the Decision Support System for the German Elbe River Basin" (2004). International Congress on Environmental Modelling and Software. 75.

https://scholarsarchive.byu.edu/iemssconference/2004/all/75

This Event is brought to you for free and open access by the Civil and Environmental Engineering at BYU ScholarsArchive. It has been accepted for inclusion in International Congress on Environmental Modelling and Software by an authorized administrator of BYU ScholarsArchive. For more information, please contact scholarsarchive@byu.edu, ellen_amatangelo@byu.edu. 
Presenter/Author Information

Jürgen Berlekamp, Neil Graf, Oliver Hess, Sven Lautenbach, Silke Reimer, and Michael Matthies 


\title{
Integration of MONERIS and GREAT-ER in the Decision Support System for the German Elbe River Basin
}

\author{
Jürgen Berlekamp $^{\mathrm{a}}$, Neil Graf ${ }^{\mathrm{a}}$, Oliver Hess ${ }^{\mathrm{a}}$, Sven Lautenbach ${ }^{\mathrm{a}}$, Silke Reimer ${ }^{\mathrm{b}}$ and Michael Matthies ${ }^{\mathrm{a}}$ \\ ${ }^{a}$ Institute of Environmental Systems Research, University of Osnabrück, Osnabrück, Germany \\ ${ }^{b}$ Intevation GmbH Osnabrück, Germany
}

\begin{abstract}
The Elbe-DSS is a tool for integrated river basin management of the German part of River Elbe basin. Various simulation models are used to assess the impact of measures such as reforestation, changes of agro-practices or efficiency of wastewater treatment plants and of external scenarios on a set of management objectives. For the assessment of nutrient and pollutant loads and impacts, MONERIS and GREAT-ER are integrated in the Elbe-DSS. MONERIS calculates nutrient inputs from diffuse and point sources on a sub catchment scale of about $1,000 \mathrm{~km}^{2}$. GREAT-ER was developed as a tool for exposure assessment of point source emissions considering fate in sewage treatment plants as well as degradation and transport in rivers. Both models work on long-term scale but results are calculated for different spatial entities. GREAT-ER divides the whole river network into small segments that are linked through a routing algorithm. To integrate both models, diffuse nutrient inputs for the sub-catchments calculated from MONERIS were distributed to the river network in GREAT-ER, where further elimination and transport processes are calculated together with inputs from point sources. As an example for measures the effects of reforestation on phosphate loads and concentrations in the river network were simulated. Results show a spatial heterogenic effect mainly influenced by the erosion pathway.
\end{abstract}

Keywords: River Basin; Water quality; Modelling; Decision Support System

\section{INTRODUCTION}

Integrated river basin management involves all management issues related to supply, use, pollution, protection, rehabilitation and many others in a river basin. An integrated approach implies that relations between the abiotic and the biotic part of the various water systems, between ecological and economic factors and between various stakeholder interests are taken into consideration in decision processes. Over the last decades river basin management has become increasingly complex. Societal demands have increased the need for an improved ecological and chemical quality of on use and protection of rivers and other water bodies. The pollution with a multitude of substances has lead to different views about strategies towards policy making for river basin management. The European Water Framework Directive consequently calls for a multidisciplinary approach of river basin management. A decision support system (DSS) for integrated river basin management of the German part of the Elbe river basin (Elbe-DSS) is currently under development, which involves taking into account chemical quality and ecological state of surface waters. Moreover, protection against flood and floodplain inundation as well as improvement of navigability is also part of the Elbe-DSS [BfG, 2000]. The Elbe-DSS is designed to assist the competent authorities in their strategic planning for establishing programs of measures and also in the communication with stakeholders and the general public.

This paper describes the integration of the models MONERIS [Behrendt et al., 1999] and GREATER [Matthies et al., 2001] for the assessment of nutrient and pollutant loads and impacts.

\section{DESIGN OF ELBE-DSS}

\subsection{General structure}

The Elbe-DSS is the first project that covers strategic water policy issues of different spatial and 
temporal scale for a large river basin. Starting from a feasibility study [BfG, 2001] user needs were identified by repeated discussion with representatives from international, national, regional and local authorities. Since many projects were carried out in the Elbe river basin after the German reunion in 1990 several simulation models and data sets have been readily available. This provided a current and comprehensive basis for the development of the Elbe DSS as a flexible and user-friendly system.
A feasibility study was conducted and lead to a preliminary system design, which was consequently stepwise refined. A set of external scenarios and measures for various management objectives were identified. Appropriate models were selected which deliver indicators to compare the impacts of specific measures and to support decisions to meet user requirements [Matthies et al., 2004]. Data sets of the catchment and river network were collected to support the model calculations.

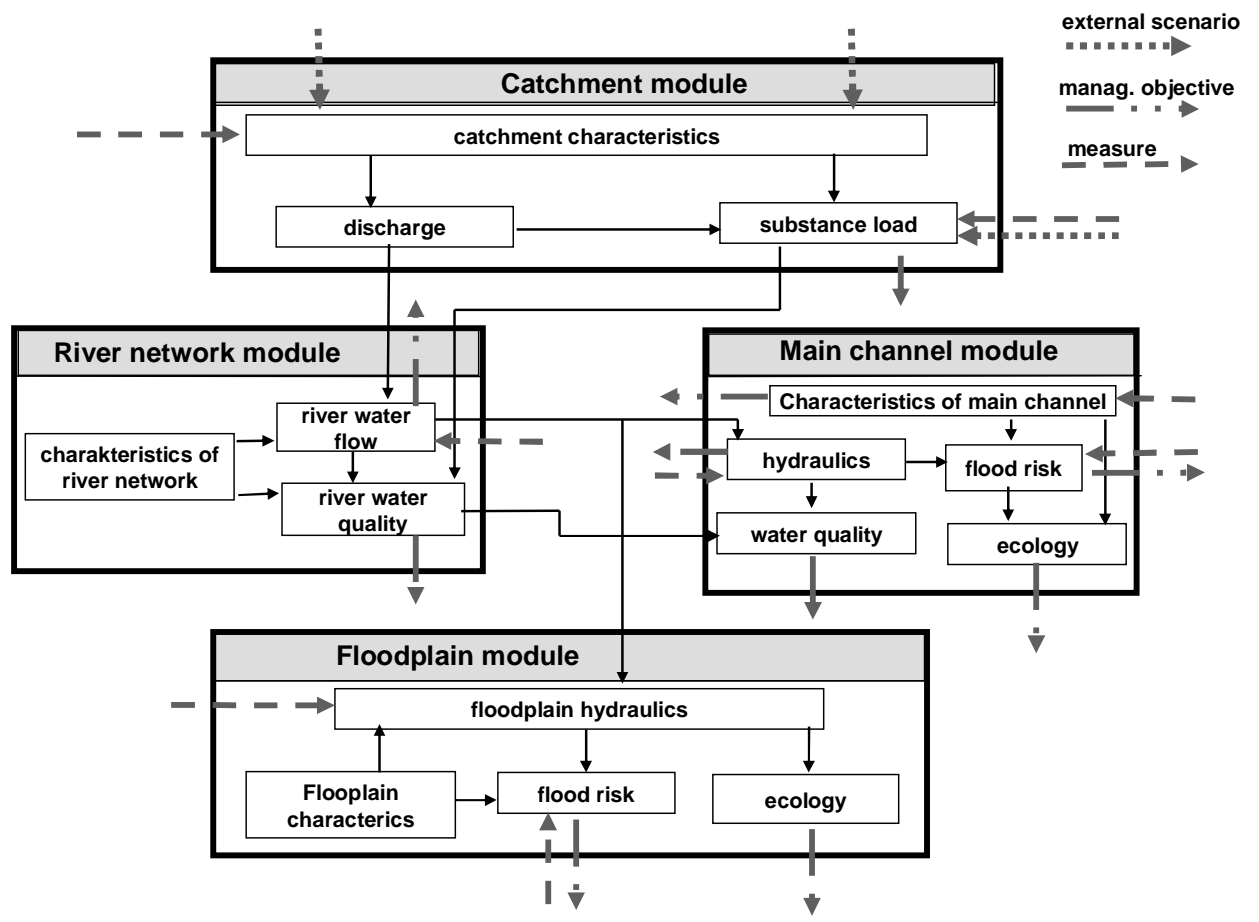

Figure 1. General systems diagram

To meet the requirements of the various spatial scales a design of four linked subsystems (modules) was chosen (Fig. 1). The catchment module assesses impacts of land use and human activities on quantity and quality of drainage components. Hydrology and water quality of the river network with $33,500 \mathrm{~km}$ river length in the German Elbe river basin is simulated in the river network module. The main channel module describes water flow and ecology only in the main Elbe river. The floodplain module characterizes in more detail hydrology and ecology in a selected river stretch of $10 \mathrm{~km}$ length.

Management objectives, external scenarios and measures are specified at the level of single modules. A management objective describes the desired status to reach legal or other requirements, e.g. reduction of substance loads. External scenarios are defined as development pathways which are determined by climatic, hydrologic, socio-economic and ecological changes (e.g. climate change). A measure means a potential action which can be chosen to reach a management objective (e.g. reforestation, reduction of impervious areas or changes of agro practice).

\subsection{Software concept}

The Elbe-DSS is implemented using the DSSgenerator software Geonamica ${ }^{\circledR}$ developed by RIKS [Hahn and Engelen, 2000]. It contains a GIS-based user interface, which allows flexible easy-to-use access to pre- and user-defined scenarios. Furthermore, a data base management system (DBMS), model base management system (MBMS) and a knowledge-based tool box are integrated under the graphical user interface. Evaluation tools have been provided for various kinds of decision-making, e.g. risk-based for hazardous pollutant concentrations, monetarybased for engineering measures or ecological services for floodplain restoration. 


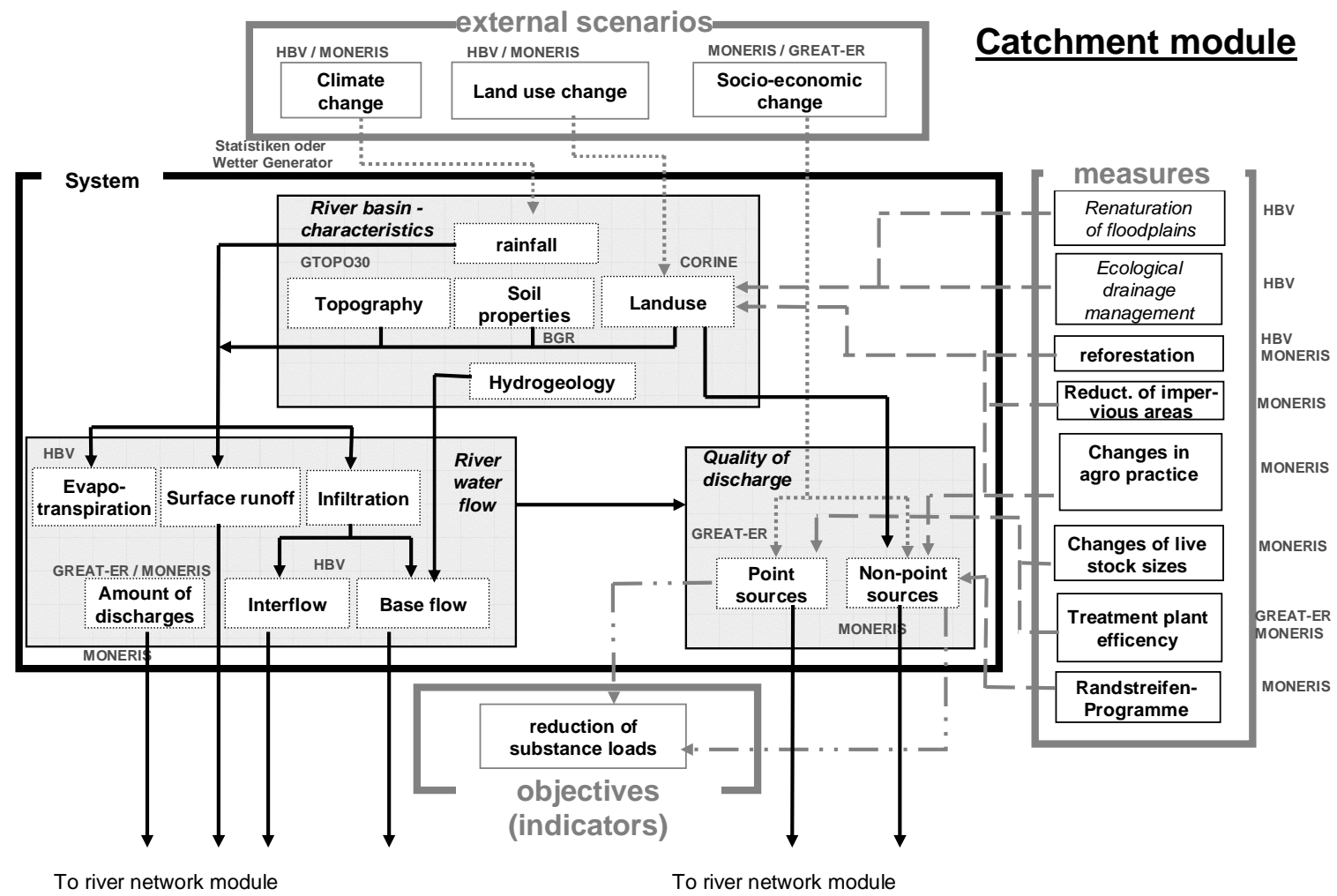

Figure 2. System diagram of the catchment module

\subsection{Integrating GREAT-ER and MONERIS}

Nutrient loads (phosphorus, nitrogen) in the ElbeDSS are calculated by the MONERIS model [Behrendt et al., 1999]. It is parameterised for 132 sub catchments in the German Elbe river basin and allows the average long-term simulation of P- and $\mathrm{N}$-loads from point and non-point sources.

For the river network, GREAT-ER is integrated into the Elbe-DSS [Matthies et al., 2001; Matthies et al., 2003]. The whole digital river network is divided into reaches of about $2 \mathrm{~km}$ length giving a number of approximately 33,500 reaches in the German part of the Elbe River (without tide influenced coastal sub-catchments). GREAT-ER delivers concentrations of hazardous substances released by point sources, e.g. sewage treatment plants. The approach is similar to the CatchMODS system of Newham et al. [2004].

Before integrating these models into the Elbe-DSS interfaces for communication of the models have to be defined. MONERIS as well as GREAT-ER are largely compatible at time and spatial scales. Both models calculate average long-term conditions without explicitly considering temporal dynamics. GREAT-ER is a steady state model and MONERIS calculates results for periods of many years. Both models focus on broad-scales and treat processes at a comparable spatial resolution.

At the current state the Elbe-DSS is able to model the nutrients nitrogen and phosphorus from point and diffuse inputs. Pollutants modelled only from point sources are diclofenac, paracetamol (pharmaceuticals), EDTA (washing agent), HHCB (polycyclic musk fragrance) and boron.

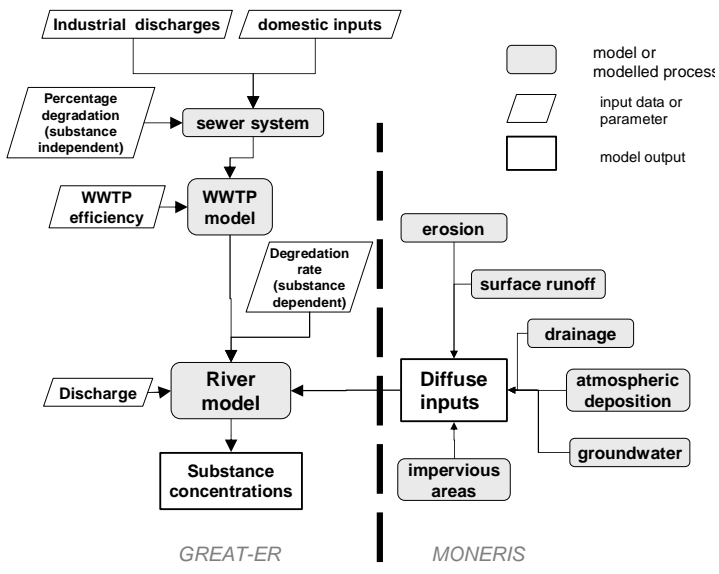

Figure 3. Scheme of integrating data and processes from GREAT-ER and MONERIS 
Some model components such as processes describing the fate of nutrients from point sources exist in both models. While MONERIS only provides overall emissions per sub-catchment, GREAT-ER takes into account locations as well as technical standards. Due to this more detailed approach that allows measures on a basis of single treatment plants this input pathway is modelled by GREAT-ER. Other details of municipal waste water treatment like sewer systems overflows are not reflected in GREAT-ER and are calculated in MONERIS. Hence the models could not be used as entire packages and it was necessary to understand and separate components of both models (Fig. 3).

The discharge of diffuse inputs into the river system calculated by MONERIS is realized by linking catchments to corresponding river reaches. The amount of diffuse emissions is distributed to the river reaches of a catchment by weighted length. In the river itself diffuse nutrient loads and inputs from point sources are merged and calculated by GREAT-ER concerning transport, decay and elimination processes.

\section{SIMULATED EFFECTS OF RE- FORESTATION ON PHOSPHORUS- LOADS AND -CONCENTRATIONS}

\subsection{Calculation}

Phosphate is a major cause of eutrophication of fresh water bodys. Large parts of the Elbe River and its tributaries are still in a eutrophic or oligotrophic state although much effort has been made in the last decade to improve the Elbe river water quality.

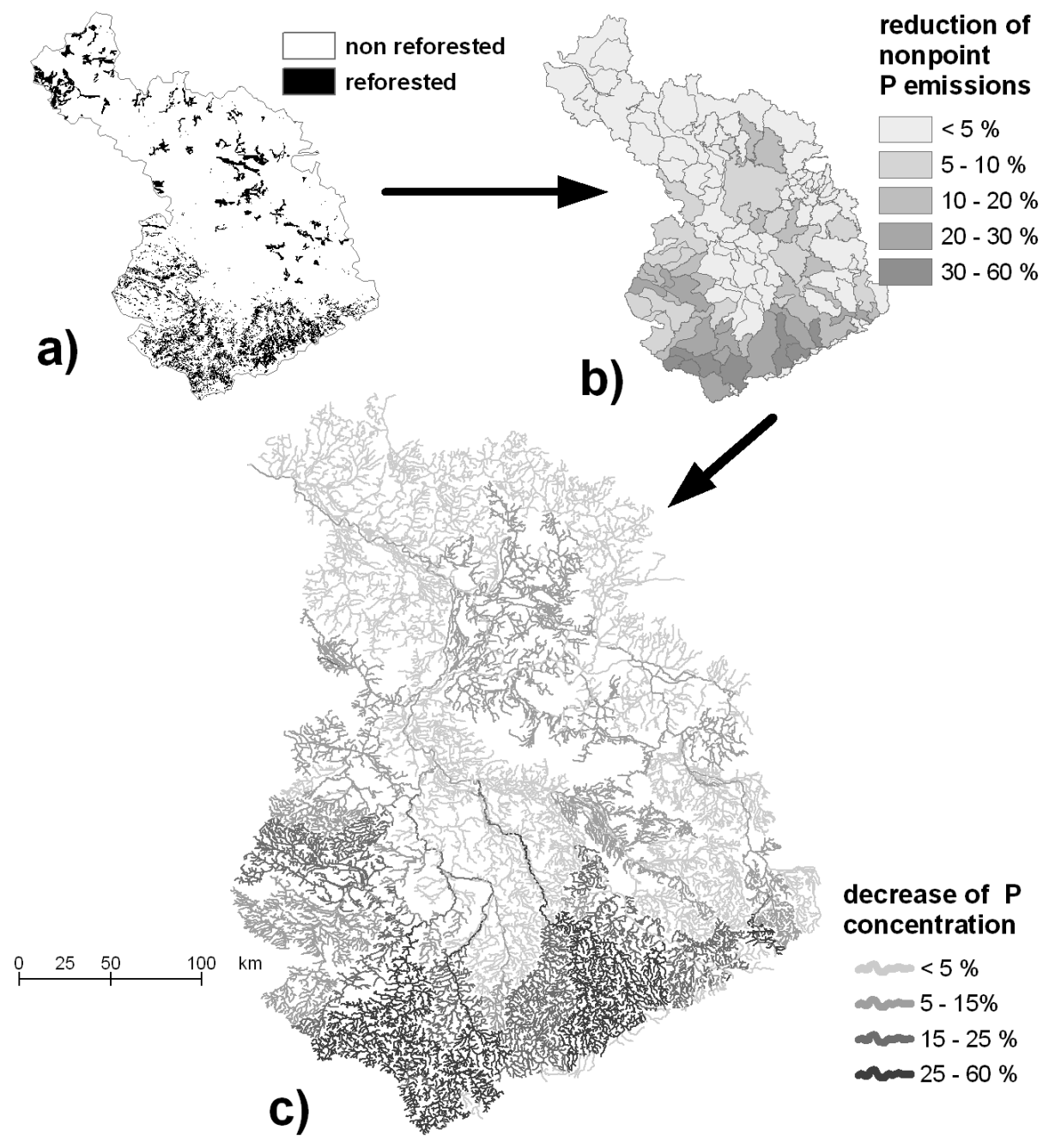

Figure 4. Effects of reforestation of agricultural crop land. Converted areas (a), reduction of phosphorus emissions (b) and resulting reduction of phosphate concentration in the river network (c) are shown.

As an example to illustrate a potential application of the DSS with the two models, the effect of a reforestation measure was analysed. For this purpose, agricultural cropping land was evaluated regarding slope and soil properties and less suitable areas for agriculture were identified 
(Figure 4a) based on this evaluation. These areas suitable for reforestation were allocated to MONERIS catchments and phosphorus emissions were recalculated. Whilst not shown in this paper, the DSS would readily allow the analysis of other options such as intensifying agriculture in other areas to compensate for production losses or erosion potential and pathways. MONERIS reforestation effects are internally represented by reducing soil mobilisation and reduction of soil loss ratio In this scenario it was assumed that the loss of agricultural crop land was not compensated by intensive agriculture in other areas.

\subsection{Results}

The low mountain range of Erzgebirge and Voigtland (south-east border of the Elbe river basin) show the strongest effect of the measure. Here, high percentages of converted areas correlate with high soil erosion caused by high relief energy (Figure 4b). Diffuse phosphorus emissions are decreased up to $60 \%$ for some catchments.

The calculated changes of P-concentrations in the river network compared to the reference situation show similar results (Fig. 4c): high reductions up to $60 \%$ occur in the streams of Erzgebirge and Voigtland. The pattern of calculated concentrations is similar to the P-emissions because variations are only caused by changes from diffuse sources and these are calculated by MONERIS on a subcatchment scale. In more detail decreases of Pconcentrations can be observed following the courses of the rivers Saale, Weiße Elster and Spree.

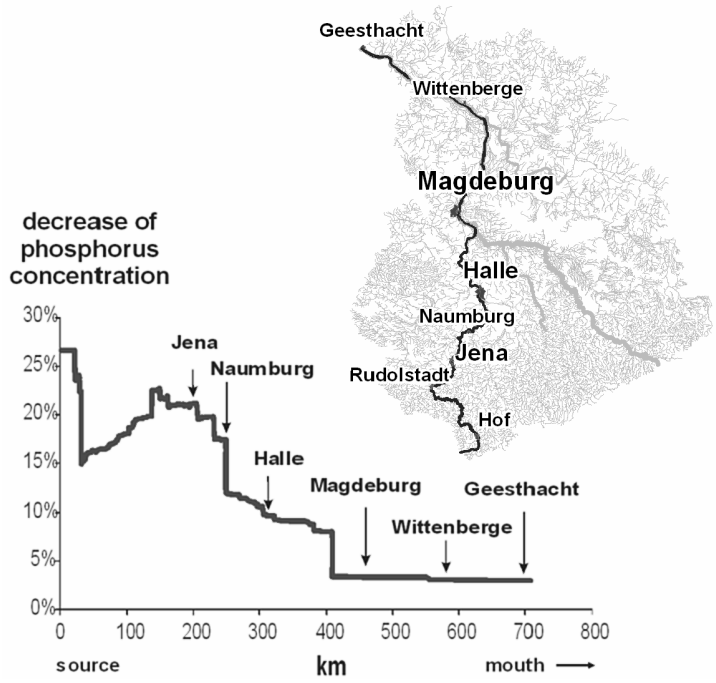

Figure 5. Effects of reforestation on the phosphorus concentration in Saale River and Elbe main channel. Relative changes on a profile from Saale headwaters to Geesthacht weir are shown.
A profile along the courses of the rivers Saale and Elbe shows relevant relative decreases of Pconcentrations mainly in the upper reaches (Fig. 5). Confluences with rivers from regions with lower reduction of erosion (inflow from river Unstrut at Naumburg, mouth of river Saale near Magdeburg) weaken this effect.

Comparisons with monitoring data allow estimating the uncertainty of the results. While monitoring data of river Elbe correspond with the model results very well (Fig. 6) differences exist for the rivers Havel, Spree and Mulde. Here model results differ from monitoring data by a relative error up to $30 \%$ which may be caused by data lacks for waste water treatment parameters or known weaknesses of modelling hydrological flow.

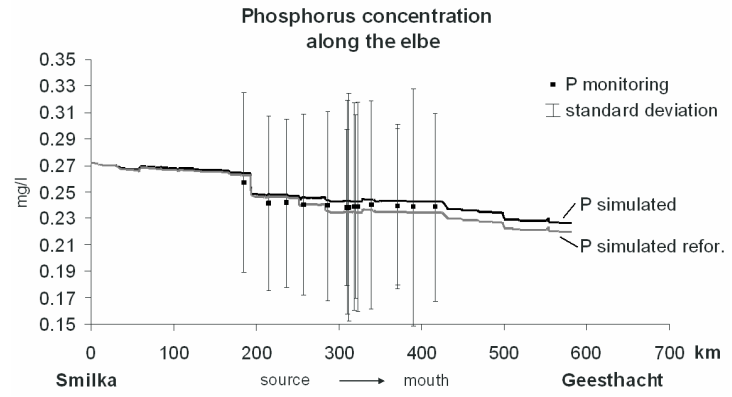

Figure 6. Comparison of simulated phosphorus concentrations with monitoring results along Elbe main channel.

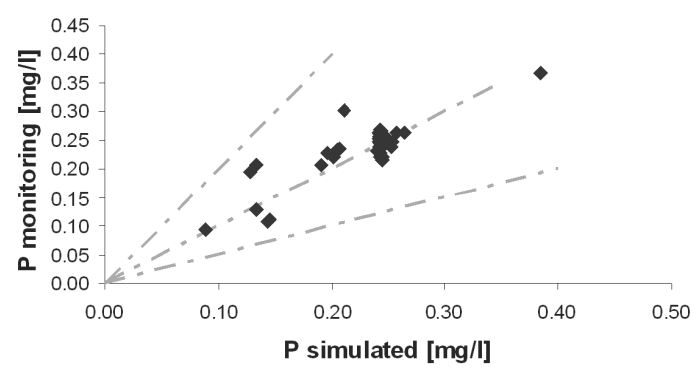

Figure 7. Comparison of simulated phosphorus concentrations with all available monitoring data.

\section{OUTLOOK}

The example of the reforestation measure demonstrates the general applicability of ElbeDDS for sustainable water management. Here the Elbe-DSS can help the user to simulate the effect of measures on the management objectives. In this case it can be used to derive the river basin management plans of the EU Water Framework Directive. 
In the next step all indented measures and scenarios will be implemented in Elbe-DSS. This also includes the main channel module and floodplain module that are not described here in detail. Model results of the integrated system has to be checked carefully also by using uncertainty analysis. It is also strongly intended to communicate uncertainty of results of the ElbeDSS to the users.

While the prototype is based on mean long-term hydrological time series, the rainfall-runoff model HBV-D [Krysanova et al., 1999] will be integrated into the final Elbe-DSS.

Tools for analysis and comparison of results will be integrated into the final software. Also tools for economical evaluation (e.g. cost-benefit analysis) will be available for selected measures and scenarios after finishing the development of the Elbe-DSS. These tools will help the user to compare different possible alternatives and prioritise management interventions. For instance it will be possible to compare measures like reforestation with changes of agro-practice or improvement of wastewater treatment plants regarding their effects on enhancing the ecological and chemical state of the rivers.

As already done for the development of the whole Elbe-DSS all intended tools will be developed in close collaboration with the end users to reach their requirements.

\section{ACKNOWLEDGEMENTS}

The authors wish to thank the DSS development team for their kind collaboration, Bundesanstalt für Gewässerkunde (German Federal Institute for Hydrology), Federal Minister for Education and Research and Federal Environmental Protection Agency for their financial support and data supply.

\section{REFERENCES}

Behrendt, H., P.-H. Huber, D. Opitz, O. Schmoll, G. Scholz and R. Uebe, Nährstoffbilanzierung der Flussgebiete Deutschlands, UBA Texte 75/99, Berlin, Germany, 1999.

BfG (Bundesanstalt für Gewässerkunde, German Federal Institute of Hydrology), Decision Support Systems (DSS) for river basin management. Koblenz, Germany, 2000.

BfG (Bundesanstalt für Gewässerkunde, German Federal Institute of Hydrology), Towards a Generic Tool for River Basin Management Feasibility study, Koblenz, Germany,2001.
Hahn, B. and G. Engelen, Concepts of DSS Systems, in: BfG 2000, 9-44, 2000.

Krysanova, V., A. Bronstert and D.-I. Wohlfeil: Modelling river discharge for large drainage basins: from lumped to distributed approach, Hydrological Sciences, 44(2), 313-331, 1999.

Matthies, M., J. Berlekamp, F. Koormann and J. O. Wagner: Geo-referenced regional simulation and aquatic exposure assessment. Water Science and Technology, 43(7), 231-238, 2001.

Matthies, M., J. Berlekamp, S. Lautenbach, N. Graf and S. Reimer, Decision Support System for the Elbe River Water Quality Management. Environmental Modelling and Software, 2004.

Matthies, M., and J. Klasmeier, Geo-referenced stream pollution modeling and aquatic exposure assessment, in: D.A. Post (Ed), ModSim 2003, Integrative Modelling of Biophysical, Social, and Economic Systems for Resource Management Solutions, Modelling and Simulation Society of Australia and New Zealand Inc., Canberra, 666-671, 2003.

Newham, L. T. H., R. A. Letcher, A. J. Jakeman and T. Kobayashi, A Framework for Integrated Hydrologic, Sediment and Nutrient Export Modelling for Catchment-Scale Management, Environmental Modelling and Software, 2004. 